\title{
As trajetórias negras encontram a institucionalidade das políticas públicas contemporâneas: ações nas comunidades quilombolas em São Lourenço do Sul, RS
}

The black trajectories found the institutionality of contemporary public policies: actions in the quilombola communities in São Lourenço do Sul, RS

\section{Patrícia dos Santos Pinheiro}

Pós-doutoranda no Programa de Pós-Graduação em Antropologia da Universidade Federal da Paraíba (UFPB) e bolsista PNPD Capes. É doutora em Ciências Sociais pela Universidade Federal Rural do Rio de Janeiro (UFRRJ) e mestre em Desenvolvimento Rural pela Universidade Federal do Rio Grande do Sul (UFRGS).

\section{Resumo}

No contexto contemporâneo brasileiro, entrecruzam-se uma pluralidade de formas substantivas de política, para além daquelas oriundas do Estado. No presente artigo serão abordadas relações estabelecidas a partir da aproximação entre ações estatais efetivadas nos últimos anos que pretensamente abarcariam a diversidade cultural e as trajetórias de comunidades negras do município de São Lourenço do Sul, Rio Grande do Sul, Brasil. Essas comunidades têm se mobilizado na busca por direitos a partir da categoria de "remanescente de comunidade de quilombo", o que representou uma possibilidade de mudanças nas estruturas de alteridade locais, mas que, no entanto, não apontou para o pleno acesso a direitos. O tema da implementação de políticas habitacionais é abordado neste trabalho a partir do método etnográfico e com uso de perspectivas teóricas que perpassam a etnicidade e o reconhecimento de grupos identitários. Dessas mobilizações, desdobram-se conflitos e negociações entre diferentes atores a partir de articulações que se materializam no cotidiano e se conectam a movimentos reivindicatórios mais amplos, trazendo um questionamento sobre processos de subordinação.

Palavras-chave: Políticas Públicas, Remanescentes de Comunidade de Quilombo, Direitos Coletivos. 


\section{Abstract}

In the contemporary Brazilian context, various substantive forms of politics intersect each other, in addition to those coming from the State. This article will discuss the relations established with the approximation of State actions carried out in the last years, which would presumably cover cultural diversity, and the trajectories of black communities in the municipality of São Lourenço do Sul, in Rio Grande do Sul, Brazil. These communities have been mobilized in the quest for rights from the category of "quilombo community remnant", which represented a possibility of changes in local alterity structures but which, however, did not point to full access to rights, exemplified by housing policies, theme addressed in this work from the ethnographic method and theoretical approaches of ethnicity and recognition of identity groups. From these mobilizations, conflicts and negotiations between different actors unfold, starting from articulations that materialize in the daily life but also connect to broader claims of the movements and raise questions on processes of subordination.

Keywords: Public Policies, Quilombo Community Remnant, Collective Social Rights.

\section{INTRODUÇÃO}

Uma das primeiras conversas empreendidas com lideranças da comunidade quilombola Rincão das Almas, em São Lourenço do Sul, Rio Grande do Sul/RS, no ano de 2012, apresentou-me a uma problemática que se mostrou recorrente desde então. Após ter exposto o tema da pesquisa à qual me dedicava naquele momento (as estratégias locais diante das intervenções sociais designadas como políticas públicas voltadas para quilombos da região) ${ }^{1}$ para a pre-

\footnotetext{
Este artigo foi elaborado a partir de trabalho apresentado na 30 ${ }^{\text {a }}$ Reunião Brasileira de Antropologia, em 2016, em João Pessoa/PB. Os dados apresentados são oriundos de pesquisa de doutorado realizada entre 2012 e 2015, quando acompanhei alguns núcleos familiares de três comunidades do município de São Lourenço, o Rincão das Almas, a Picada e a Vila do Torrão, sendo que principalmente as duas primeiras serão referenciadas. Em alguns locais, a comunicação foi feita inicialmente via associação comunitária e depois se expandiu, caso do Rincão das Almas; em outros, fui sendo apresentada pelos quilombolas (em especial os mais velhos) a partir de seus laços de parentesco internos ou entre comunidades, caso da Vila do Torrão e da Picada, nas quais as conversas com aqueles que ocupam cargos na associação foram as últimas a ocorrerem. Ou seja, os caminhos traçados foram muito diversos e certamente incompletos. Entrevistas ou conversas com agentes mediadores do poder público sobre a pesquisa se deram mais ao final desse período. A partir de 2015, atuei em projetos de extensão nas comunidades quilombolas Rincão das Almas e Maçambique (município de Canguçu) e em laudos antropológicos em duas comunidades da região (Monjolo, também em São Lourenço, e Maçambique).
} 
sidente da associação quilombola na época, que estava também acompanhada do vice-presidente, ambos relataram as dificuldades no encontro entre o que os agentes mediadores de diferentes políticas públicas - que de modo inédito se aproximavam daquele território - traziam como oportunidades e o que se constituía como prioridade para as cerca de 100 famílias do Rincão das Almas.

A presidente ainda ponderava que, mesmo que essas "oportunidades" (como cursos, projetos, equipamentos etc.) fossem desejáveis, havia ali um desafio de grandes proporções, considerando que as normas para execução de tais ações, tensionadas pelos interesses das próprias organizações executoras, não necessariamente condiziam com as sociabilidades, dissensões e estratégias quilombolas, diante de um duro e não tão distante passado de racismo e de estigmatização do qual a comunidade buscava se recompor.

Ao apontar alguns exemplos críticos desses desafios, um fator que se destacou foi a configuração interétnica que aproximou, naquele local (pois em outros lugares do mesmo município se processou de modo contrário), aqueles que se identificam ou são identificados como quilombolas, morenos ou de raça negra dos colonos (de origem majoritariamente pomerana) e dos tucas ou brasileiros (descendentes de portugueses ou sem uma pertença étnica). Ao fim da conversa, o vice-presidente reafirmou a postura de acolhimento praticada na associação ${ }^{2}$ : Não sei se o que a gente está fazendo é o certo, mas aqui colono casa com negro. Já a presidente justificava essa prática - que se destacava como uma transgressão às normas sociais da região e que unia, em especial, pessoas que compartilhavam a escassez de recursos materiais - dizendo que apenas seguia seu coração, mesmo já tendo sido questionada sobre essa receptividade a partir de argumentos que buscariam deslegitimar este território negro que se autoidentifica como quilombola.

As duas lideranças prosseguiram a conversa afirmando que as fronteiras entre quilombolas e não quilombolas não se definem apenas por uma variável, mesmo que relevante, mas sim por um emaranhado de fatores que rementem

\footnotetext{
Termos nativos serão indicados em itálico na primeira vez em que aparecerem, assim como trechos de entrevistas. Os nomes foram omitidos em situações que possam prejudicar os sujeitos da pesquisa. No caso das organizações executoras da política de habitação, optou-se pelas letras X e Y no lugar dos nomes.
} 
à constituição e manutenção do território, na qual algumas formas de diferenciação persistiram ao longo do tempo e outras não. Relacionam-se, desse modo, à etnicidade, a qual não se trata de um fenômeno imutável ou isolado de traços culturais, mas sim é retrabalhada na memória coletiva desses grupos que se mantiveram em interação ao longo do tempo, com a formação e reformulação de critérios de pertença e repulsa (BARTH, 2011).

$\mathrm{O}$ acolhimento narrado pelas lideranças do Rincão, todavia, não anula as diferenças, mas as torna mais complexas, mostrando distintas configurações em termos de estatutos e de fatores sociais que se mantiveram relevantes nesta região de pertencimentos étnico-raciais específicos, dado o contexto histórico, social e político da fronteira sul do Brasil. Por exemplo, em intensidades variáveis, também se expressam relações de trabalho consideradas injustas entre patrões (colonos e/ou fazendeiros) e empregados (quilombolas, brasileiros ou colonos), expropriações fundiárias, preconceito racial, uso da língua pomerana como fator de distinção etc. (cf. PINHEIRO, 2016).

$E$ nesse contexto que as interfaces com agentes mediadores do acesso a direitos e ao reconhecimento de comunidades quilombolas representaram a possibilidade de mudanças nas condições de vida e em estruturas de alteridade. Com problemática semelhante, em outra comunidade do mesmo município - a Picada, que na época tinha mais de 20 famílias associadas - a aproximação se dava com as localidades de Fazenda Tunas e Cerro Chato, onde há concentrações de brasileiros ou colonos descapitalizados, muitos com parentesco entre negros há várias gerações.

Tanto na Picada quanto no Rincão das Almas, apesar da constatação dessas dissonâncias, a aproximação de agentes externos trazia certo alento, mesmo que as experiências iniciais tivessem apresentado uma série de adversida$\operatorname{des}^{3}$ e que por vezes não fosse claro quais seriam esses direitos - Os direitos universais que lhes eram negados? A valorização de suas práticas, recorrentemente estigmatizadas? A regularização fundiária? - e como seria viabilizada

No Rincão, uma primeira associação foi formada nessa comunidade no início dos anos 2000; porém, a denúncia de mau uso de recursos por parte da ONG que prestava assessoria ao grupo levou alguns moradores a formarem uma nova associação com atuação de outra ONG, que atualmente é a única ativa. Na Picada, desavenças em função de recursos externos também ocorreram. 
sua execução. Além disso, chamava a atenção a intensidade inédita de agentes que procuravam as comunidades quilombolas, oriundos de organizações não governamentais (ONG), algumas delas gerenciadas por organizações vinculadas a igrejas, mas também agentes municipais, estaduais ou federais e, ainda, pesquisadores ou participantes de movimentos sociais do município e de outros locais, gerindo recursos públicos e privados por meio de projetos e programas.

Para as duas comunidades que serão aqui apresentadas (mas não somente), as articulações vistas como possíveis foram marcadas pela inserção em políticas públicas a partir de meados dos anos 2000, mediadas por ONG ou por órgãos públicos de atuação consolidada no contexto rural, mais do que por algum conflito fundiário explícito, como em outros locais do Brasil. Um marco desse processo no Rio Grande do Sul foi o programa RS Rural, criado em 1997 com recurso do Banco Mundial e executado até 2005 pela Empresa de Assistência Técnica e Extensão Rural (Emater), que em um primeiro momento se voltava à agricultura familiar de maneira geral, mas, a partir de 2001, rearticulou-se pelas demandas de grupos diferenciados, dentre os quais se inseriram cerca de 50 comunidades quilombolas (SOUZA; FERNANDES; RUBERT, 2005). Em São Lourenço, o programa foi acessado para a construção e reforma de casas, incluindo banheiros de alvenaria, compra de animais de criação, arames para cercas e máquinas. Após essas primeiras ações, foram formadas associações quilombolas que se tornaram um importante canal de suas atividades.

Outro marco dessa aproximação foi o apoio da Secretaria do Desenvolvimento Territorial do extinto Ministério do Desenvolvimento Agrário (SDT/ MDA) - que a partir de 2016 se tornou uma secretaria dentro da Casa Civil ao projeto de Mapeamento das Comunidades Quilombolas do Território Zona Sul, executado pela ONG Centro de Apoio e Promoção da Agroecologia (Capa) entre 2008 e 2009 (CAPA, 2010). O mapeamento, que foi parte da política de inclusão social do Programa Territórios da Cidadania, mostrou a expressividade numérica das comunidades quilombolas, com a listagem de 43 delas na região, com destaque para o município vizinho de Canguçu, além da presença de comunidades nos municípios vizinhos de Cristal, Piratini, Pelo- 
tas, Arroio do Padre, Morro Redondo, Jaguarão e Turuçu, entre outros ${ }^{4}$. Após o mapeamento, houve uma significativa expansão da assessoria técnica de diferentes organizações, em especial voltadas ao mundo rural ou a serviços de assistência social.

Essas ações, porém, não resultaram na garantia dos almejados direitos. Não se tratando de uma relação polarizada entre Estado e comunidades autoidentificadas como quilombolas, ocorreram diversos reposicionamentos ao longo do tempo em termos de adesões a determinadas políticas e a seus gestores e/ou financiadores e parcerias foram feitas e desfeitas, seja de quilombolas com brasileiros e colonos, seja deles com agentes mediadores. De modo a problematizar as implicações de tal processo, o objetivo deste artigo será refletir sobre os encontros (e desencontros) entre os sujeitos mencionados em um contexto de interações e tensionamentos.

Entre as dinâmicas atuais de organização política e as tortuosas trajetórias de territórios negros no Brasil, recompõe-se e amplia-se o campo de relações no qual se inserem esses grupos sociais. Associada a lutas sociais de diferentes grupos minoritários, essa ampliação é também fruto de uma perspectiva de pluralismo que permitiu o reconhecimento de formas de organização que fugiam do recorte de classe, com a problematização de elementos como etnia, gênero e preservação ambiental. Parte de um processo mais amplo, a promoção de reformas constitucionais e de políticas de identidade que reverberaram em diferentes países da América Latina nas últimas décadas do século XX, incluindo o Brasil, propunha-se a abarcar a diversidade cultural no interior dos Estados nacionais (VAN COTT, 2000). Para além da América Latina, essas mudanças podem ser visualizadas no âmbito do direito internacional pelos pactos de direitos civis e outros dispositivos, com a instituição, em 1989, da Convenção 169 da Organização Internacional do Trabalho (OIT) (FIGUEIREDO, 2011).

\footnotetext{
No Sul do Brasil, um primeiro mapeamento das comunidades negras foi realizado em 1996, como lembra Rubert (2005), coordenado pelo Núcleo de Estudos Sobre Identidade e Relações Interétnicas (NUER), da Universidade Federal de Santa Catarina (UFSC). No Rio Grande do Sul, o trabalho resultou em laudos técnicos em seis comunidades (nenhuma da região de Pelotas) no início dos anos 2000.
} 
Cada qual com sua história e suas mobilizações, dentre esse conjunto de grupos sociais que buscam reconhecimento e acesso a direitos no Brasil, estão os "remanescentes de comunidades de quilombos". Com uma proposta distinta da homogeneidade nacional operada até então, estão presentes no texto constitucional de 1988 de modo fragmentado: no artigo 68 do Ato das Disposições Constitucionais Transitórias (ADCT), que dá enfoque à regularização fundiária, e no artigo 216, voltado à patrimonialização da cultura brasileira, o qual determina o tombamento de documentos e locais com "reminiscências históricas dos antigos quilombos". Além disso, direitos culturais de afrodescendentes são mencionados no artigo 215 (BRASIL, 1988).

O autorreconhecimento das comunidades tem como instância institucional a Fundação Cultural Palmares (FCP), que emite certidões a partir da demanda das comunidades, e o Instituto Nacional de Colonização e Reforma Agrária (Incra), vinculado à Secretaria da Agricultura Familiar e do Desenvolvimento Agrário (antigo MDA). O Incra se ocupa das etapas da regularização fundiária, regida pelo Decreto nº 4.887/2003, e respectivas instruções normativas, nas quais o título das terras é conferido a associações comunitárias (BRASIL, 2003)

No artigo, em um primeiro momento apresentarei dados sobre os territórios negros de São Lourenço, conectados com um debate sobre como se deu a chegada do quilombo, com critérios, discursos, estratégias e práticas específicas para o acesso a políticas públicas. Posteriormente, serão apresentadas al-

\footnotetext{
Para um histórico das leis, decretos e outros instrumentos que versam sobre o reconhecimento das comunidades quilombolas e seus questionamentos, ver Arruti (2010). Podem ser mencionadas tanto ações que apontam para supostas inconstitucionalidades no processo (Ação Direta de Inconstitucionalidade - ADI n 3.239/2004, julgada improcedente pelo STF em fevereiro de 2018) quanto propostas de emendas constitucionais, reforçando a fragilidade de um reconhecimento efetivo. Como exemplo, tramita desde 2000 no Congresso a Proposta de Emenda Constitucional (PEC) n²15, de autoria do ex-deputado da bancada ruralista Almir Sá, que altera os artigos 49 e 231 da Constituição Federal e prevê que a demarcação de terras tradicionalmente ocupadas pelos povos indígenas e a ratificação das demarcações já homologadas passasse pelo Congresso Nacional (hoje, são de responsabilidade do Executivo). A ratificação das demarcações pelo Congresso foi considerada inconstitucional, porém o seu aval para demarcações futuras segue tramitando e, apesar de não constar na proposta original, a alteração de outros artigos, como o art. 68 do ADCT (que era alvo da PEC 161/2007) passou a ter tramitação conjunta em 2009. Mais recentemente, a essa matéria também foram associadas emendas de plenário apresentadas em nome da Comissão Parlamentar de Inquérito (CPI) da Fundação Nacional do Índio (Funai) e Incra 2, que tem operado a criminalização e deslegitimação do trabalho de antropólogos e técnicos destas instituições. A tramitação pode ser acompanhada em: https://bit.ly/2BfOMRx. Acesso em: 15 abr. 2018.
} 
gumas reflexões sobre a implementação de uma política específica, a habitacional. Para compreender melhor essa configuração, utilizarei bibliografias referentes ao debate sobre reconhecimento de identidades, como Fraser (2007), além de autores que abordam a etnicidade, como o já mencionado Barth (2011).

\section{“QUANDO O QUILOMBO CHEGOU...”}

De local combatido e criminalizado pelo poder público a local de reconhecimento identitário, é significativo visualizar o longo histórico de transformação do termo "quilombo" no Brasil (ARRUTI, 2008). Com o texto constitucional, impasses conceituais se colocam diante das inúmeras dinâmicas sociais que se relacionam às comunidades quilombolas e que foram limitadas a uma única categoria, situação que com frequência remete a uma ideia cristalizada de pertencimento étnico. Como saída, a categoria remanescente de quilombo foi associada à noção de grupo étnico de Barth (LEITE, 2000), além das contribuições sobre o conceito de terras de uso comum e territorialidade, que enfatizam as relações de pertencimento das pessoas com um lugar e seus modos de vida, não a uma noção de quilombo histórico (ALMEIDA, 2010). Apesar das dificuldades na normatização e definição das competências, o quilombo também assumiu significado de reconhecimento desses atores como sujeitos de direito, não somente uma memória a ser preservada (LEITE, 2000).

Diante da complexidade das categorias locais e da maneira como se relacionam com a sua memória dos processos históricos, no universo da pesquisa, uma intrigante e recorrente expressão é utilizada para demarcar temporalmente o início de um diálogo mais estreito com o poder público em diferentes escalas nas comunidades de São Lourenço, como na implementação do RS Rural ou na formação das primeiras associações quilombolas: Quando o quilombo chegou... ou ainda Depois do quilombo.... A chegada do quilombo, nessas falas, não se trata de uma etnogênese estimulada pelo poder estatal ou seus representantes, como à primeira vista poderia parecer. Marca sim o momento em que se iniciam aproximações de distintos atores externos com 
fins de estimular o acesso destas comunidades a ações de reconhecimento. $\mathrm{Na}$ região, as comunidades negras eram com frequência identificadas por outros grupos como constituídas por morenos, vinculadas ao rural, porém até então invisíveis ao poder público enquanto identidade coletiva e alvo de enraizadas situações de subordinação como mão de obra pouco valorizada na região, conforme abordado em Pinheiro (2016).

Cabe aqui ressaltar que, como lembram Anjos e Leitão (2009), a demarcação de distintividades já vinha se estabelecendo muito antes do texto constitucional fazer referência a esses grupos:

A diferenciação étnica em relação ao entorno antecede a autodefinição de uma comunidade quilombola. Quando a comunidade se afirma como quilombola, é porque ao estigma, os moradores responderam com a afirmação positiva da diferença étnica (ANJOS; LEITÃO, 2009, p. 19).

Para os autores, a distintividade étnica, para além de traços culturais primordiais e uma determinada constituição biológica, expressa a fronteira étnica, em que:

[...] expressar significa exibir modos de existência como marcas peculiares de um território cultural. A fronteira étnica é o resultado de um modo de organização das diferenças, em que danças, cantos, modos de trabalhar, de rezar, traços de fenótipo, entre outros, carregam um grupo para um limiar étnico de expressividade. Isso significa que o gesto político de exibir a distintividade não vem depois da diferença étnica, mas é a política de diferença que é a condição da possibilidade do contraste étnico (ANJOS; LEITÃO, 2009, p. 16).

Com adaptações constantes, a trajetória dos grupos negros de São Lourenço remonta ao período da escravidão, muito marcante nessa região pela concentração de cativos nas charqueadas em Pelotas (município do qual São Lourenço se emancipou), que nos séculos XVIII e XIX abasteciam o comércio interprovincial com charque, um tipo de carne conservada no sal (OSÓRIO, 2007). No que hoje corresponde ao município de São Lourenço, as áreas de campo foram ocupadas a partir do século XVIII por luso-brasileiros esta- 
belecidos em grandes estâncias agropecuárias. Já as áreas mais íngremes, ainda esparsamente povoadas (oficialmente "vazias"), tinham pouco valor econômico e em meados do século XIX foram loteadas pela elite local para formação de colônias de origem teuto (BOSENBECKER, 2011). O primeiro desses projetos foi a chamada Colônia de São Lourenço, estabelecida a partir de 1858 com imigrantes da extinta Pomerânia (que englobaria parte da Alemanha e da Polônia) na serra dos Tapes, que chegou a abrigar 20 desses projetos em municípios como Pelotas, Canguçu, São Lourenço e adjacências (ZARTH, 2002).

Na implementação da Colônia de São Lourenço, os recém-chegados imigrantes encontram uma elite de origem luso-brasileira e escravista que concentrava o acesso à terra e posições administrativas, jurídicas e do poder repressor (BOSENBECKER, 2011). Em geral, cativos, forros, quilombolas, lavradores sem terras, indígenas e outros sujeitos subalternos pouco aparecem quando se trata da história dessa região. No entanto, com terras férteis e certa tranquilidade, essa serra já se apresentava como um refúgio e rota de fuga pelo menos desde o início do século XIX (MAESTRI, 2002) ${ }^{6}$.

O quilombo, tal qual identificado no período escravista, abrangia os mais diversos agrupamentos, como grupos itinerantes, comunidades negras mais estáveis com uma economia de subsistência, ou ainda grupos muito pequenos, inclusive em espaços urbanos (MAESTRI, 2002), apesar de possuir etimologia bantu distinta (kilombo), que significava uma associação transétnica de guerreiros, política e militar, segundo Munanga (1995). Dada a infinidade de configurações contemporâneas, não é possível se fixar nos marcos conceituais do período colonial, que tinha uma ênfase dirigida ao quilombola como cativo fugido para locais isolados e distantes (ALMEIDA, 2002).

E é na serra dos Tapes que se dá um momento marcante na constituição de, pelo menos, quatro das atuais comunidades do município de São Lourenço do Sul, que foi a fuga de um grupo de 13 cativos, na segunda metade do século XIX, de uma estância no município de Canguçu, diante da iminência de

\footnotetext{
Expedições de recaptura de cativos fugidos nessa área são documentadas a partir de 1820. Dentre os inúmeros casos de aquilombamento na serra dos Tapes, o que se destaca é o do bando de Manoel Padeiro, que exigiu grande mobilização das autoridades no ano de 1835, às vésperas da Revolução Farroupilha (MAESTRI, 2002; MOREIRA; AL ALAM; PINTO, 2013).
} 
um castigo coletivo. O grupo se dispersou em três para evitar a recaptura por parte das autoridades, assentando-se em São Lourenço, na localidade de Cantagalo e suas adjacências, onde formaram as comunidades de Faxinal de Baixo (atualmente Vila do Torrão), Serrinha (Monjolo) e Faxinal de Cima e, na localidade de Santa Tereza, da Picada. Essas comunidades cresceram com a chegada de novos moradores e mantiveram diálogo constante entre si e com moradores de outros territórios negros (PINHEIRO, 2015; RUBERT, 2005).

Na Picada, seu Molina, dona Loni e sua filha Sandra, da família Ferreira, apontam uma peculiaridade em relação à mencionada fuga coletiva de cativos no seio de sua família: uma criança, Aparício Ribeiro, avô de seu Molina, perdeu-se do grupo e foi encontrada e criada por uma família de origem germânica moradora dos arredores do atual território da Picada. Além de Aparício, que ali se estabeleceu, famílias negras que trabalhavam com um fazendeiro, conhecido como Coronel Centeno, também teriam se fixado no local, em área cedida por ele, mantendo deslocamento sazonal para trabalhar em tais terras. Dona Maria Ferreira Ribeiro (in memoriam), irmã de seu Molina, complementa lembrando que muitos anos depois a área foi parcialmente retomada pelo filho do fazendeiro, o que culminou com uma situação considerada injusta, pois houve expulsão de duas anciãs de suas habitações, que tiveram de ser acolhidas em outras residências.

Já o Rincão das Almas, anteriormente conhecido como Rincão dos Negros ou Boa Vista dos Forros, está localizado em uma área mais plana, próxima à BR 116 (rodovia construída em meados do século XX) e da sede do município. Como relata seu Guilherme Rodrigues, um dos moradores mais antigos da comunidade, as terras do Rincão foram doadas por uma estancieira aos seus cativos, em especial a família Pereira (que ainda reside na comunidade), com relatos vagos sobre o período da doação. Essa doação foi registrada em um mapa com a localização e extensão da herança (1.501 braças), entregue na década de 1960 a um vizinho da comunidade para que encaminhasse ao poder público, na tentativa de realizar a regularização das terras. Porém, o famoso mapa foi extraviado e jamais encontrado. 
Os territórios negros eram considerados locais de acolhimento e refúgio e o Rincão foi um local de grande recepção de parentelas negras, que foram se estabelecendo ou circulando entre outros territórios. Se a mobilidade pode ser considerada uma forma de liberdade, o enraizamento em um território era importante para a estabilidade das famílias negras, fato que no pós-abolição também representou um desafio, diante de recorrentes espoliações de territórios e da exploração como mão de obra pouco valorizada que levava à migração. Essas trajetórias incluíram tanto estratégias de inserção como trabalhadores precarizados - por vezes em troca de comida (cevadura), roupas e ferramentas em criações de gado, na rizicultura e, mais recentemente, na fumicultura quanto formas de distanciamento prudente de uma sociedade pouco acolhedora em função do uso de mecanismos de segregação.

Partilhando do mesmo espaço rural, um sistema interétnico peculiar se constituiu no município, que engloba pertencimentos e delimitações entre grupos que se diferenciam localmente e são fundados a partir da interação em circunstâncias e graus variáveis (BARTH, 2011; CARDOSO DE OLIVEIRA, 1976). Nesse processo, certos elementos de diferenciação ganham relevância e são reforçados por alguns grupos pelo enaltecimento de qualidades próprias e a consequente desqualificação do outro. No caso, pelo uso da língua pomerana, pela pretensa maior capacidade de trabalho dos colonos (apesar de todo histórico de trabalhos extenuantes que vivenciou a população negra nessa região), pela religiosidade ou tradições culturais etc.; enquanto outros elementos perdem força ao longo do tempo e permitem reordenamentos nesse sistema, incluindo casamentos interétnicos. Assim, mesmo morando no interior da colônia e sendo agricultores (uns com e outros sem propriedade de terra que permita a agricultura comercial), com base na experiência histórica, política e cultural, fronteiras foram formadas e fortalecidas entre colonos, quilombolas e brasileiros.

O interesse em relatar esses elementos não se restringe a uma "listagem" de traços culturais delimitadores. Sua importância reside no fato de que fazem parte de complexos sistemas de organização social que precisam ser descritos para uma análise das configurações atuais, que incluem novas possibi- 
lidades de conquistas como grupo quilombola, também calcadas em lutas silenciosas, em que permanecer no território em uma região disputada do ponto de vista da ocupação fundiária já é uma afronta.

As hierarquias sociais também foram entrecruzadas nessas classificações e, mesmo entre grupos que se diferenciariam, solidariedades são forjadas, como é o caso das relações entre famílias que compartilham de situações econômicas desfavoráveis, por vezes unindo colonos, brasileiros e quilombolas em laços mais próximos. Sendo a identidade étnica contrastiva, afirmando-se pela negação de outras e por vezes de forma conflitiva, essas interações permitem a reconstrução das categorias de exclusão e pertencimento, que contam também com transformações individuais nos critérios de pertencimento a cada grupo. Fatores externos, como as restrições legais ao racismo e as políticas públicas voltadas à diversidade, também influenciaram essas reconfigurações.

Mas a percepção como sujeito de direitos, evidentemente, carrega limites sobre quais direitos está se falando, de que maneira eles poderiam ser materializados, quais seriam as parcerias e a que custo as ações acabam sendo efetivadas. As políticas públicas não são vistas somente como um fim em si, mas também como possibilitadoras de um reposicionamento desses grupos no interior das relações locais, em especial na quebra de hierarquias (DUTRA, 2011). Por exemplo, em uma configuração mais recente, com o suporte de projetos para a produção agrícola quilombola, não seria mais necessário se submeter a baixas remunerações ou troca de trabalho por utensílios, sementes ou animais para a produção própria, situações recorrentes segundo os relatos dos quilombolas. Assim sendo, não haveria a possibilidade de exploração de seu trabalho como em outros tempos e a alimentação estaria assegurada por programas sociais ou aposentadorias.

Nessas ações estatais, está em jogo a atuação em diferentes esferas públicas de participação, respeito aos modos de vida e o controle efetivo dos recursos e seus territórios, elementos que se relacionam com o acesso a direitos. Entre outros autores que abordam a questão, Fraser (2007) reflete sobre formas de acionamento de universalidade e da diferença em termos de direitos sociais a partir de uma reflexão sobre a aproximação entre políticas de redistribuição e 
de reconhecimento, frequentemente polarizadas em políticas de classe e políticas de identidade ${ }^{7}$. Para a autora, redistribuição e reconhecimento são fundados em linhagens filosóficas diferenciadas (moral e ética) e compõem dois campos de reivindicação distintos, um relacionado à justiça, outro à boa vida. Delas resultariam, respectivamente, ações distributivas depreciadas por serem utilizadas com objetivo de mitigar alguns efeitos do capitalismo sem de fato modificar nenhuma estrutura ou políticas de identidade, as quais são criticadas quando atuam na reificação da cultura e em certa fragmentação da sociedade.

Fraser considera que simplesmente fundir reconhecimento com redistribuição é problemático, pois há a necessidade de historicizar as suas ligações dada a complexidade com que os atores se articulam de acordo com suas estratégias - e aponta para a possibilidade de combinar aspectos emancipatórios (FRASER, 2007). A autora sugere que o reconhecimento seja operado no campo da moralidade, em que o que se reconhece é a condição de subordinação, pois universalismo e processos identitários não são necessariamente contraditórios como fenômenos sociais. No caso de São Lourenço, sem reconhecer essa relação entre identidade e subordinação, por exemplo, grupos que se autoidentificam como distintos, como os quilombolas, pomeranos, pescadores artesanais e outros, não teriam explicitadas as diferentes condições históricas, políticas e sociais que conformaram suas trajetórias e que fazem com que atualmente suas demandas (como acesso à terra, educação, saneamento etc.) não sejam idênticas.

Mas, afinal, o que poderia contemplar modos de existência que resistiram, cada um a seu modo, a formas de opressão históricas vinculadas, direta ou indiretamente, ao período escravocrata? E atualmente, o que seria mais importante para assegurar que esses grupos identitários tenham poder de escolha?

Como aponta Leite (2000), ao enfatizar as experiências de organização social dos quilombos, estão em jogo direitos territoriais, sucessórios, sociais e culturais. Para Figueiredo (2011), o reconhecimento como sujeitos coletivos

\footnotetext{
Honneth (2003), por exemplo, considera que a luta social também é permeada por concepções morais de justiça, em que não ter acesso a determinados elementos - que seriam de direito - pode ser visto como uma questão de dignidade.
} 
de direito e politicamente imagináveis como grupo étnico valorizado pode garantir não somente direitos especiais (relacionados à religiosidade, memória e territorialidades específicas), mas também um acesso diferenciado a direitos universais. Dentre eles, estariam ações como a alfabetização, o saneamento, a geração de renda, o estímulo a esportes, relações justas de trabalho, acesso à infraestrutura básica, lazer, eletrificação rural, entre outros, com interfaces com o Programa Brasil Quilombola, criado em 2004, sob coordenação da Secretaria Especial de Políticas de Promoção da Igualdade Racial (SEPPIR).

Em São Lourenço do Sul, a partir dos anos 2000, as comunidades passaram a fazer parte, enquanto quilombolas, da rota de ações do poder público. Dentre elas, destacam-se as ações Fome Zero, Luz para Todos (a partir de 2006), o Programa Nacional de Documentação da Trabalhadora Rural (PNDTR) e o Balcão da Cidadania, com a confecção de carteira de identidade, CPF, carteira de trabalho e número de identificação do trabalhador, além de informações sobre aposentadoria e outros, o Programa Nacional de Habitação Rural (PNHR), a ampliação do Bolsa Família para o espaço rural, a autocertificação das comunidades quilombolas pela FCP e a abertura dos processos para a regularização fundiária no Incra ${ }^{8}$, o Programa Nacional de Alimentação Escolar (PNAE) e Programa Fomento às Atividades Produtivas, dentre outros. Há ainda o acesso à Declaração de Aptidão ao Programa Nacional de Fortalecimento da Agricultura Familiar (DAP) (BRASIL, 2013).

Além dessas, entre as ações que atualmente incidem ou já foram efetivadas junto às comunidades, pode ser mencionado o incentivo à geração de renda. Cursos de artesanato, de padeiro, de alimentação saudável, de uso de plantas medicinais, de horticultura, distribuição de sementes e mudas de árvores, assistência técnica produtiva e recebimento de equipamentos, como instrumentos musicais e máquinas de costura, são alguns exemplos (PINHEIRO, 2015).

Inicialmente, muitas dessas práticas eram executadas dentro de uma agenda mais ampla voltada ao espaço rural, efetivadas mais intensamente na

\footnotetext{
A regularização fundiária, previsa na Constituição brasileira, atualmente tem seu processo administrativo normatizado pelo Decreto ${ }^{\circ} 4.887$ (BRASIL, 2013), com a titulação permanecendo com associação quilombola de cada território, após a mesma percorrer as várias etapas do processo, da autocertificação até a titulação.
} 
região junto ao programa interministerial Território da Cidadania9 ${ }^{9}$ A categoria de agricultura familiar na região que engloba as comunidades aqui mencionadas exerceria, em tese, papel aglutinador junto a diferentes atores, como agricultores familiares, assentados pela reforma agrária e grupos étnicos, para ações coletivas de fortalecimento de um espaço rural diverso culturalmente. Porém, apesar do discurso oficial de diversidade, as organizações que atuam em nome da agricultura familiar possuem interesses que podem ser incompatíveis com alguns direitos sociais aos quais as comunidades quilombolas teriam acesso, caso da regularização territorial, que poderia englobar disputas territoriais com colonos.

A partir de 2012, muitas dessas ações passaram a compor o Plano Brasil Sem Miséria, em especial aquelas voltadas para a universalização de alguns serviços, como acesso à água, assistência técnica, benefícios sociais, inclusão produtiva, entre outros. Com isso, ações com enfoque no reconhecimento de especificidades perdem destaque. Mas, para além de uma checagem das atividades desenvolvidas ou das metas atingidas em uma ação estatal, é preciso problematizar o que essas diversas ações significaram para os atores implicados no processo. Com a acentuação do discurso de erradicação da pobreza, um novo pressuposto de homogeneidade se coloca, trazendo tensionamentos entre a ideia de combate à pobreza e as expressões quilombolas.

\section{A TRAJETÓRIA DAS HABITAÇÕES QUILOMBOLAS: POLÍTICA, NEGOCIAÇÃO E ENFRENTAMENTO}

Diziam que antes os brancos tiravam do negro, mas hoje também tiram dos negros (Dona Eva, Rincão das Almas, 2013).

\footnotetext{
9 O programa Território da Cidadania foi iniciado em 2008 em diversas localidades do Brasil a partir dos Territórios Rurais, configurando-se como um canal de integração de políticas interministeriais direcionadas a grupos específicos do espaço rural que se encontram em situação de vulnerabilidade socioeconômica.
} 
No auge das discussões sobre os problemas gerados pelas tentativas de acesso a políticas de habitação, o trecho supracitado expressa a preocupação desta liderança com a atualização de formas de exploração dos quilombolas a partir de projetos e programas que iniciaram e não tiveram continuidade, os quais visavam interesses externos à comunidade ou ainda que foram executados sem considerar as especificidades de cada grupo e tendem a gerar a desagregação dos elos comunitários. As decisões de cada comunidade acabam por englobar essa tensão entre o acesso a políticas públicas e a desconfiança em relação aos possíveis parceiros.

Com a justificativa de tirar pessoas da precariedade de moradia, o Programa Nacional de Habitação Rural (PNHR), parte do Programa Federal Minha Casa Minha Vida (PMCMV), foi criado em 2009. O programa subsidia a construção ou reforma de moradias no meio rural e é realizado por meio de organizações de assistência técnica e dos governos estaduais e federal (BOLTER; SCHNEIDER; HAAS, 2015; BRASIL, 2013) ${ }^{10}$. Para acessarem o programa, os "beneficiários" devem estar vinculados a uma entidade organizadora (EO), que pode ser o próprio poder público, cooperativas, associações ou outros, responsável pela elaboração do projeto, execução das obras e prestação de assistência e capacitação a esses grupos, com subsídio de $\mathrm{R} \$ 1$ mil por família para a assistência técnica (CAIXA..., 2013). A partir de 2013, esse programa, que já havia sido executado de modo significativo para o público da agricultura familiar de São Lourenço, passou a disponibilizar projetos específicos para quilombos, dado que os mesmos ainda não acessavam tal política.

Em casos como este, a parceria de atores externos foi considerada como estratégica pelas lideranças do Rincão e da Picada. No entanto, a execução do programa se tornou emblemática, em função de disputas entre organizações executoras que se colocavam como mediadoras. Em um primeiro momento,

\footnotetext{
${ }^{10}$ Diversas casas dessas comunidades já eram de alvenaria antes do programa e foram feitas com recursos próprios ou com materiais oriundos do Programa RS Rural; necessitariam apenas de reparos (pois continham rachaduras e eram sem rebocos, sem banheiros ou fossas, por exemplo). A opção de reforma pela Caixa teria subsídio de até R\$ 15 mil (SEPPIR, 2013) e o relato das lideranças é de que, inicialmente, havia essa opção; porém, com o passar do tempo, o que foi apresentado como possível foram as casas novas.
} 
apenas uma $\mathrm{EO}$ encaminhou projeto para construção de habitações quilombolas nessa região (que será chamada aqui de organização X), para a qual famílias de diversas comunidades chegaram a entregar sua documentação. No entanto, após anos de espera pelas habitações, algumas associações quilombolas decidiram solicitar suas casas por intermédio de outra organização, a organização $\mathrm{Y}^{11}$. Este conflito gerou uma tensão que se multiplicou em diversas comunidades, pois o controle na execução da política não ficou concentrado em uma única organização, dando uma margem de escolha para as lideranças quilombolas sobre qual organização executaria a construção em cada local, que não foi ignorada e fez parte das negociações acerca da continuidade das parcerias a longo prazo.

Nesse processo, intercalam-se considerações de ordem moral e o aproveitamento de oportunidades, baseadas em noções de justiça distintas. Para o presidente da Associação da Picada na época da assinatura dos contratos, investir em uma parceria com a primeira organização não era estratégico, pois, em sua avaliação, essa organização, além de não priorizar as demandas quilombolas (as famílias deste quilombo estavam esperando há três anos por um retorno na documentação enviada), já não tinha mais o mesmo capital político, o que se refletia também na imagem que ele tinha do poder político para pleitear futuras ações para a sua comunidade.

Por um lado, a organização Y realizou uma verdadeira campanha nos quilombos (apesar de não ter um trabalho anterior nesses locais), aproximando-se de quilombolas que estavam insatisfeitos com a atuação da primeira e a demora na liberação dos contratos. A decisão se fortaleceu com a comunicação entre as comunidades, que partilharam suas estratégias de seleção da EO e possibilitou uma apropriação de outra maneira da política pública ${ }^{12}$. À medida que eram informadas dessa nova possibilidade, as comunidades foram

\footnotetext{
${ }^{11}$ Ambas são vinculadas a trabalhos com agricultura familiar. O valor subsidiado variou de $\mathrm{R} \$ 25$ mil a R\$ 28,5 mil para a construção das casas, com contrapartida de $4 \%$, em parcelas anuais, complementados por convênios estaduais para o pagamento de pedreiros e serventes (CAIXA..., 2013).

12 Mais do que a burocracia estatal, essas lideranças argumentavam que havia um descaso no encaminhamento dos contratos, salvo algumas comunidades que teriam sido priorizadas por terem um trabalho mais intenso com a organização X.
} 
fazendo (parcialmente ou totalmente) a mudança em relação à EO, o que parecia dar forças para uma escolha que poderia ter implicações no trabalho de assistência técnica da organização X há anos ${ }^{13}$. A decisão compartilhada por inúmeras comunidades fortaleceu suas estratégias de resistência e possibilitou uma apropriação de outra maneira da política pública, apesar dos conflitos no processo. Por fim, em algumas comunidades optou-se por manter contratos com ambas organizações, a critério de cada família, de modo que em algumas apenas uma foi escolhida.

No Rincão, em uma das visitas à casa da presidente da associação, pude acompanhar, por acaso, a entrega dos documentos dessa comunidade a representantes da organização Y para o encaminhamento dos contratos. Era um dia de nervosismo, pois, com esse ato, não se sabia como seria a reação dos parceiros iniciais da organização X. Por outro lado, estavam revoltados com a demora na implementação do projeto. Antes dos representantes chegarem, ela e outra liderança, uma das matriarcas da comunidade, expuseram-me, em uma breve conversa, tais argumentos, citando outros quilombos que também tomariam a mesma decisão.

Os representantes da organização $\mathrm{Y}$, ao chegarem, mostraram um vídeo com a fala de um dos moradores mais velhos da comunidade quilombola do Monjolo, que foi estreitamente ligado ao trabalho da organização X, mas agora a criticava de modo contundente, o que tornou esse rompimento muito significativo. Mais ainda foi o fato de ele ter que acessar essa política pela associação de outro quilombo, a Vila do Torrão, dado que naquele local a opção da associação foi permanecer com a primeira organização. ${ }^{14}$

Ainda durante a entrega dos documentos do Rincão, a fala dos representantes da organização Y tratou de fortalecer seu próprio trabalho, incluindo a estratégia de depreciar a atuação profissional e a vida pessoal de ex-téc-

\footnotetext{
${ }^{13} \mathrm{Na}$ Vila do Torrão, antes de tomar a decisão, a liderança solicitou uma reunião com a organização X, por contato telefônico, e a resposta da técnica contatada foi enfática: Quem sabe quem tem que marcar reunião somos nós, não vocês. Diante do que foi considerado um autoritarismo, a liderança foi taxativa: com essa postura, eles procurariam a outra entidade.

${ }_{14}$ Todavia, não é possível dizer se esse senhor tinha dimensão de estar sendo filmado para posterior divulgação de seu vídeo em outras comunidades.
} 
nicos da outra organização. Vendo que a conversa não mudava de rumo, nesse momento a matriarca da comunidade esclareceu que não confiava plenamente em nenhuma das organizações, que sabia até onde ir para melhorar a vida na comunidade. Posteriormente, conversando sobre o episódio, ela comentou que, mesmo sabendo que ninguém é santo, na sua concepção se torna necessário ter relação com essas organizações. Ao fim, ela deixou explícito que a comunidade decidiria quem seriam os seus parceiros.

Dado o desgaste desse período de espera, muitas famílias demonstravam descrença com a execução dessa política, já cansados da presença de agentes externos desengajados: É melhor nem vir, se é assim, disse-me dona Maria Ferreira Ribeiro, da Picada, que optou por não demandar uma nova moradia, por achar que sua casa precisaria apenas de uma reforma, assim como a família de seu irmão, seu Molina Ferreira. Na Picada, a comunidade acabou fazendo projetos pelas duas organizações.

Outro ponto importante é o olhar dessas organizações locais que executaram a política sobre as próprias comunidades quilombolas e seus modos de vida, que, por exemplo, consideravam as casas de barro, por muito tempo utilizadas por famílias quilombolas na região, como casebres (CAIXA..., 2013). Os casebres, no caso, tratavam-se de casas que com o passar do tempo se tornaram sinal de estigmatização para essas famílias. As casas de barro eram feitas de torrão (em grandes leivas de terra com vegetação gramínea, que firmava o bloco de terra) ou de pau a pique (barreado com um entrelaçado de madeiras ou taquaras), cobertas por capim santa fé. Aos poucos foram substituídas por casas de alvenaria, dado que as casas de barro tinham risco de desmoronamento de paredes em épocas de chuva e de incêndios em função do telhado.

Porém, essas casas que atualmente são indicadas como símbolo de atraso e parte do tempo antigo (como os quilombolas se referem ao passado), mantêm vivas as memórias afetivas sobre o território e também remetem a boas recordações - dos momentos de cantoria em volta do fogão à lenha dentro de uma cozinha de barro, da mãe que sabia construir feito o pássaro joão de barro, com muita alegria; dos mutirões para construção; da estabilidade térmica 
(quente no inverno e fria no verão) etc. A casa de barro chega a ser apontada, em especial pelos mais velhos, como elemento que poderia ser reconstruído, mas como um memorial de um tempo em que viveram dificuldades extremas e assim também demarcar mudanças em relação ao tempo antigo, que, do mesmo modo que outros fatores, como a alimentação escassa, o isolamento e a relação com os colonos, parcialmente também se modificou. Por terem sido tomados por atores externos como marcadores sociais de diferenciação negativa, já não caberiam mais no atual contexto e, em geral, quando aparecem, são como uma lembrança persistente desse tempo.

As moradias de barro, sendo um desses demarcadores, eram diretamente vinculadas ao ser negro na região, em um contexto de forte estigmatização e de deslocamentos em busca de trabalho na região. Por conta disso, eram construídas distantes das estradas, como relatam seu Molina Ferreira e sua filha Sandra:

Molina: Ah, o pessoal se mudava. De repente estava na casa do colono, aí o colono não queria mais, aí tinha que se mudar, aí outro pessoal pegava também, aí arrumavam um cantinho para ele e escondiam o negro no meio do mato.

Sandra: Isso que eu ia dizer. [...] Sempre o negro morava dentro do mato, não era na beira da estrada. Eu lembro que a minha vó mesmo, que morava no Evaristo, nós íamos visitar a vó, claro, depois eles foram morar mais na beira da estrada, mas a primeira moradia que eles mostravam assim para a gente, era bem lá dentro do mato. Aí depois eles vieram mais para frente, aí depois eles vieram para a beira da estrada. Era uma coisa que parecia que ficava sempre se escondendo (Família Ferreira, Picada, 20 nov. 2013).

Ao sair do meio do mato e abandonar as casas de barro, a autopromoção feita a partir do ato de depreciar o outro - por esse traço escolhido externamente como distintivo - é rompida, mesmo tendo que abandonar algumas práticas e demonstrando a impossibilidade de se expressarem em seus próprios termos. Sem as casas de barro, um dos elementos de diferenciação externo é apagado, mas, ao mesmo tempo, um ponto importante dos sistemas 
de referência internos ao grupo é deixado de lado e assume-se um outro discurso para ser "incluído" na sociedade englobante.

Outro fator de depreciação das casas de barro se deu com a atuação de órgãos públicos voltados à assistência social e ao saneamento, quando estes estabeleceram que tais construções poderiam disseminar insetos indesejáveis como o barbeiro, sem atentar para o cultivo de plantas repelentes ou para a qualificação das casas. Prepondera, dessa maneira, o saber técnico-científico, com traços higienistas, sobre saberes locais, em nome de uma noção de saúde idealizada e dedutiva que exerce supremacia sobre elementos culturais. Também a instalação da luz elétrica nas casas era indicada por esses agentes como incompatível com as casas de barro, pelo potencial de incêndio dos telhados de capim santa fé. Algumas casas, porém, mantiveram seus alicerces e algumas paredes com a técnica de torrão, sendo posteriormente cobertas por acabamentos de cimento.

Enfatizar que as casas eram casebres no âmbito da execução da ação estatal, por outro lado, coloca o trabalho das organizações como essencial para modificar uma condição de falta e alçar os quilombolas à posição de moradores de uma habitação "moderna", abandonando qualquer resquício das casas antigas. A justificativa de "trazer o desenvolvimento" é acompanhada de uma autopromoção das instituições ou pessoas que disputam a presença como mediadores nas comunidades, seja como representantes das demandas comunitárias, seja como parceiros no acesso a políticas públicas.

Se, por um lado, essas relações com uma rede de mediadores materializada pelas políticas públicas compõem estratégias de obtenção de direitos antes inacessíveis por causa do preconceito racial e da desigualdade jurídica e social, por outro, o que é ofertado frequentemente são ações restritas e por vezes descontextualizadas. Durante a construção das casas do PNHR na região, muitos foram os questionamentos junto às organizações responsáveis, por exemplo sobre a qualidade do material e a própria planta da casa - que não seria condizente com o que foi acordado - e sobre o acompanhamento das obras. Por exemplo, foram recorrentes situações em que os tijolos e telhas eram frágeis, o piso tinha má qualidade, as aberturas que seriam 
de alumínio na verdade são de outro material (como um latão), os trabalhadores contratados para a construção não cumpriam suas tarefas etc. Estes casos eram solucionados (quando eram) após duras reclamações das lideranças junto às organizações. ${ }^{15}$

Nesse episódio, há uma tensão na apropriação que tenta resolver a violência ontológica junto a esses grupos, mas que ao mesmo tempo pode implicar em uma mudança que não foi fruto somente de opções internas, relegando as casas de barro somente ao tempo antigo. Mas, mesmo com uma série de percalços no acesso a uma política anteriormente inalcançável, uma dimensão de autoestima está em jogo por meio da apropriação de símbolos hegemônicos, como habitações de alvenaria. No Rincão, a construção das casas foi considerada uma grande vitória e gerou ainda um movimento de retorno e repovoamento da comunidade, cujos motivos seria a oportunidade de acesso a esses programas de habitação e outras políticas públicas. Se com o passar do tempo muitas das pessoas que moravam nesse território foram vendendo a terra por acharem que não era bom morar ali, atualmente a configuração é distinta. Vendiam a terra por nada ou por comida, para tentar a vida na cidade - ou, como observa uma das interlocutoras do Rincão, Ieda Mourão, era para passar trabalho na cidade.

Tanto no Rincão quanto na Picada, o mesmo debate que houve na formação da Associação Quilombola - sobre a presença de parceiros, vizinhos e parentes brancos descapitalizados - seguiu como um ponto de divergência na implementação do PNHR. Há os que consideram que todos aqueles que são próximos da comunidade, simbolicamente partilhando a categoria de moreno e, posteriormente, quilombola, ou que com ela se identificam de alguma forma e necessitam da política, devem poder acessá-la. Essa pode ser considerada uma estratégia para operar mudanças locais, dentro de uma perspectiva do quilombo como local de refúgio, em que a comunidade passa a estar em uma posição distinta da estigmatização.

\footnotetext{
${ }^{5}$ Além disso, esse programa não se propõe a dialogar com outras ações do poder público nos mesmos territórios, como nos locais em que está em curso a regularização fundiária.
} 


\section{REFLEXÕES FINAIS}

Da questão social relativa ao diálogo de grupos identitários com agentes do poder estatal por meio de políticas, programas e projetos públicos, ocorreria a afirmação de um modelo pluralista presente no texto constitucional. Nessa aparente mudança nos discursos hegemônicos, haveria uma frágil abertura para a institucionalização da relação do Estado com diferentes grupos locais, em que os modos de existência e trajetórias de vida construídos ao longo do tempo pelos grupos negros encontram as ações do poder público sob novas perspectivas - não mais somente como poder repressor - e o reconhecimento de uma identidade de determinado grupo abriria a possibilidade do questionamento de processos de subordinação e da pluralização de direitos.

Para tanto, as comunidades quilombolas recorrem a uma releitura da própria história da escravidão, que pode incluir uma exposição do enraizamento de uma série de injustiças e distinções raciais praticadas durante e após a instauração do sistema econômico vinculado ao regime escravista no Brasil, seja a partir de ações de reconhecimento e afirmação (como metáfora à resistência negra), seja a partir da reparação com ênfase na inclusão, a qual é justificada como maneira de sanar dívidas históricas oriundas de desdobramentos do período escravista.

Também está em jogo a realização do controle e da regulamentação da gestão do território e das pessoas, no qual as políticas públicas se materializam no plano local a partir de diversas restrições e acomodações, diante das relações de força internas ao próprio Estado, com oscilações entre autoridade, legitimidade e negligência diante dos seus objetivos unificadores. Essas ações, dessa maneira, acabam assumindo uma perspectiva de integração subordinada dentro de um sistema de controle estatal, reforçadas nos processos de mediação e assistência técnica e organizativa de diferentes atores que assumem a posição de elaboradores e gestores de intervenções junto a esses grupos (que por sua vez respondem a esse processo de maneiras diversas).

Evidentemente, práticas aparentemente contraditórias perpassam a administração pública e expressam as relações e tensões presentes entre modos de ordenamento e projetos políticos distintos representados de modo assimétri- 
co na gestão pública, tanto em sua escala local quanto regional e nacional. Ademais, entre os gestores das instituições estatais e de organizações de mediação e as elites locais pode haver o compartilhamento de visões de mundo sobre qual papel caberia às comunidades quilombolas nos programas e projetos em curso.

Em âmbito local, tais ações não podem se desvincular das interações entre pertencimentos e distintividades entre morenos, colonos e brasileiros. Não obstante, se a visão reproduzida em diferentes escalas é frequentemente a de subalternidade, as reconfigurações atuais não levaram à formação de uma simples clientela e, no caso em questão, há uma apropriação das políticas como um meio para modificar relações locais de subordinação e não como um fim em si. Dito isso, o entendimento é de que as políticas públicas aqui mencionadas são fruto de uma complexa interação entre poder público e sociedade, com infinita diversidade de interesses em jogo.

Passados alguns anos dessa aproximação entre comunidades e poder público, há um misto de descrença e esperança. Onde há continuidade das atividades, as famílias parecem ter conquistado um pouco mais de autonomia em relação às organizações externas, buscando novos parceiros que procurem não reproduzir situações consideradas desrespeitosas. Por outro lado, não participar das atividades coletivas, quando elas representam a desunião ou uma nova forma de exploração, é uma outra forma de resistência, mesmo que se abra mão de possíveis direitos. Entre elementos estruturais e a agência dos inúmeros atores que fazem parte da formulação e execução dessas ações, constituíram-se diferentes estratégias e relações em seu reconhecimento enquanto sujeitos coletivos de direitos, sejam de resistência, de apropriação local, de ressignificações dos processos políticos e identitários e também de transgressão dos "resultados esperados" por essas intervenções quando as dissonâncias entre as diferentes reivindicações locais e as classificações e expectativas criadas junto às comunidades quilombolas se destacam.

Mas, em um intervalo entre a mudança almejada e a possível e entre os polos de autonomia e tutela, há um mundo de ações cotidianas, formas como as pessoas vivem as políticas públicas e parcerias estratégicas que compõem a luta por direitos sociais e a melhoria das condições de vida. Esse "viver" mostra uma potência crítica e subversiva, muitas vezes silenciosa. 


\section{REFERÊNCIAS}

1. ALMEIDA, Alfredo Wagner Berno de. Terra de preto, terra de santo, terra de índio: uso comum e conflito. In: DELGADO, N. G. (org.). Brasil rural em debate: coletânea de artigos. Brasília: MDA; Condraf, 2010. p. 104-131.

2. ALMEIDA, Alfredo Wagner Berno de. Os quilombos e as novas etnias. In: O’DWYER, Eliane Cantarino. (org.). Quilombos: identidade étnica e territorialidade. Rio de Janeiro: FGV, 2002. p. 43-82.

3. ANDRADE, Maristela de Paula. Novos sujeitos de direitos e seus mediadores: uma reflexão sobre processos de mediação entre quilombolas e aparelhos de Estado. Antropolítica, Niterói, n. 27, p. 43-61, 2009.

4. ANJOS, José Carlos; LEITÃO, Leonardo. Etnodesenvolvimento e mediações político culturais no mundo rural. Porto Alegre: UFRGS, 2009.

5. ARRUTI, José Maurício. Antropologia e Direito nos embates em torno dos quilombos no Brasil. Paper apresentado em mesa redonda derechos y justicia social: las luchas por reconocimiento em Brasil, Colombia y Ecuador. In: Congresso Latinoamericano de Sociologia Rural, 8., 15-19 nov. 2010, Porto de Galinhas, Pernambuco.

6. ARRUTI, José Maurício. Quilombos. In: PINHO, Orlando Araújo; SANSONE, Lívio. (org.). Raça: perspectivas antropológicas. Salvador: EDUFBA, 2008.

7. BARTH, Fredrik. Grupos étnicos e suas fronteiras. In: POUTIGNAT, Philippe; STREIFF-FENART, Jocelyne. Teorias da etnicidade. 2. ed. São Paulo: Unesp, 2011. p. 185- 228.

8. BOLTER, Jairo Alfredo Genz; SCHNEIDER, Sergio; HAAS, Jaqueline Mallmann. O Programa Nacional de Habitação Rural como estratégia de inclusão e desenvolvimento rural. In: GRISA, Catia; SCHNEIDER, Sergio. (org.). Políticas públicas de desenvolvimento rural no Brasil. Porto Alegre: UFRGS, 2015. p. 465-484.

9. BOSENBECKER, Patrícia. Uma colônia cercada de estâncias: imigrantes em São Lourenço/RS (1857-1877). 2011. Dissertação (Mestrado em História) Universidade Federal do Rio Grande do Sul, Porto Alegre, 2011.

10. BRASIL. Constituição da República Federativa do Brasil. Brasília, DF: Senado Federal, 1988.

11. BRASIL. Decreto $n^{\circ} 4.887$, de 20 de novembro de 2003. Regulamenta o procedimento para identificação, reconhecimento, demarcação e titulação das terras ocupadas por remanescentes das comunidades dos quilombos. Diário 
Oficial da União, Brasília, 21 nov. 2003. Disponível em: http://bit.ly/2DWX5Uc. Acesso em: 1 mar. 2013.

12. BRASIL. Secretaria Nacional de Políticas de Promoção da Igualdade Racial. Guia de políticas públicas para comunidades quilombolas. Brasília (DF), abril de 2013. Disponível em: https://bit.ly/2NopdZv. Acesso em: 16 abr. 2017.

13. CAIXA beneficia mais de 1.700 famílias de quilombolas. Caixa Econômica Federal (Imprensa), Brasília, 2013. Disponível em: https://bit.ly/2DW7pM2. Acesso em: 14 set. 2013 .

14. CARDOSO DE OLIVEIRA, Roberto. Identidade, etnia e estrutura social. São Paulo: Livraria Pioneira Editora, 1976.

15. CAPA (Centro de Apoio ao Pequeno Agricultor). Revelando os quilombos no Sul. Pelotas: Capa, 2010.

16. DUTRA, Maria Vanessa Fonseca. Direitos quilombolas: um estudo do impacto da cooperação ecumênica. Rio de Janeiro: Koinonia, 2011.

17. FRASER, Nancy. Reconhecimento sem ética? Lua Nova, São Paulo, v. 70, p. 101138, 2007.

18. FIGUEIREDO, André Videira de. O caminho quilombola: sociologia jurídica do reconhecimento étnico. Curitiba: Appris, 2011.

19. GOFFMAN, Erving. Estigma: notas sobre a manipulação da identidade deteriorada. São Paulo: LTC, 2004.

20. HONNETH, Axel. Luta por reconhecimento: a gramática moral dos conflitos sociais. São Paulo: Editora 34, 2003.

21. LEITE, Ilka Boaventura. Os quilombos no Brasil: questões conceituais e normativas. Etnográfica, Lisboa, v. 4, n. 2, p. 333-354, 2000.

22. MAESTRI FILHO, Mário. Deus é grande, o mato é maior: história, trabalho e resistência dos trabalhadores escravizados no Rio Grande do Sul. Passo Fundo: UPF, 2002.

23. MOREIRA, Paulo Roberto Staudt; AL ALAM, Caiuá Cardoso; PINTO, Natália Garcia. Os Calhambolas do General Manoel Padeiro: práticas quilombolas na serra dos Tapes (RS, Pelotas, 1835). São Leopoldo: Oikos, 2013.

24. MUNANGA, Kabengele. Origem e histórico do quilombo na África. Revista USP, São Paulo, n. 28, p. 56-63, 1995.

25. OSÓRIO, Helen. O império português no sul da América: estancieiros, lavradores e comerciantes. Porto Alegre: UFRGS, 2007. 
26. PINHEIRO, Patrícia dos Santos. Pertencimentos, fronteiras e intersecções: processos de identificação em São Lourenço do Sul, Rio Grande do Sul. Norus, Pelotas, v. 4, n. 5, p. 7-35, 2016.

27. PINHEIRO, Patrícia dos Santos. Políticas de identificação: dinâmicas de reconhecimento identitário de comunidades negras rurais no sul do Brasil em um contexto de relações interétnicas. 2015. Tese (Doutorado em Ciências Sociais em Desenvolvimento, Sociedade e Agricultura) - Instituto de Ciências Humanas e Sociais, Universidade Federal Rural do Rio de Janeiro, Rio de Janeiro, 2015.

28. RUBERT, Rosane Aparecida. Comunidades negras rurais do RS: um levantamento socioantropológico preliminar. Porto Alegre, RS Rural/IICA, 2005.

29. SOUZA, Cledis Rezende de; FERNANDES, Mariana Balen; RUBERT, Rosane Aparecida. Comunidades negras rurais do RS: o trânsito rumo à autoidentificação como quilombola. Observatório Quilombola, 1 jun. 2005. Disponível em: http:// bit.ly/2SsYGVv. Acesso em: 1 jun. 2010.

30. VAN COTT, Donna Lee. Democratization and constitutional transformation. In: VAN COTT, Donna Lee. The friendly liquidation of the past: the politics of the diversity in Latin America. Pittsburgh: University of Pittsburgh, 2000. p. 1-35.

31. ZARTH, Paulo Afonso. Do arcaico ao moderno: o Rio Grande do Sul agrário do século XIX. Ijuí: Unijuí, 2002. 